\title{
EFFECTS OF LIGHT INTENSITY AND SPECTRAL COMPOSITION ON THE GROWTH AND METABOLISM OF SPINACH (SPINACIA OLERACEA L.)
}

\section{Lörinc Utasi' ${ }^{1,2}$, István Monostori'1, Balázs Végh ${ }^{1}$, Zoltán Pék $^{2}$ \& Éva Darkó ${ }^{*}$}

${ }^{1}$ Hungarian Academy of Sciences, Centre for Agricultural Research, Agricultural Institute, H-2462 Martonvásár, Brunszvik str. 2, Hungary; ${ }^{2}$ Szent István University, Faculty of Agricultural and Environmental Sciences, H-2100 Gödöllö, Páter Károly

str. 1, Hungary; *E-mail: darko.eva@agrar.mta.hu

\begin{abstract}
Spinach rich in proteins, minerals (Fe, K) and antioxidants (vitamin C) is often cultivated in greenhouses under artificial light. In this study, the effects of light intensity and spectral composition provided by light emitting diodes (LEDs) was studied on the yield quality and quantity of spinach. Plants were grown under 3 different light intensities $\left(100 / 200 / 300 \mu \mathrm{mol} \mathrm{m} \mathrm{m}^{-2} \mathrm{~s}^{-1}\right)$ and 3 spectral compositions (white/white completed with blue or far-red) for 4 weeks. Then plant weight, leaf number and area, photosynthetic activity and pigment composition of leaves were determined. The leaf quality was characterized by measurements of protein, starch, soluble sugar and ascorbate contents of leaves. Moreover, minerals ( $\mathrm{K}, \mathrm{Fe}$ and $\mathrm{NO}_{3}^{-}$) were also determined. While the biomass production was mainly determined by the light intensity, the yield quality is influenced significantly by the spectral composition. When the white light was supplemented with blue, high protein and ascorbate content was achieved. When far-red was added to white light, elevated sugar and Fe accumulation was observed in the leaves, while the K content decreased. In order to reach the hight quality and quantity of food production, not only the light fluence, but also the spectral composition should be regulated.
\end{abstract}

Keywords: LED lighting, spinach, hydroponics, artificial light

\section{INTRODUCTION}

Light is one of the most important environmental factors that affect plant growth and development. Through photosynthesis and the operation of photoreceptors, both the light intensity and the spectral composition have broad regulatory effects on the morphogenesis, such as leaf growth and expansion, on many 
physiological and metabolic processes in plants, which finally determines the main characteristics of plants: the appearance and quality.

With the use of artificial light in phytotrons, greenhouses and in modern plant factories, the light environment of plants inherently changes compared to the natural light situation. This influences multiple aspects of plant functioning, including photosynthesis, photomorphogenesis, water relations, nutritional quality, biomass and yield production and quality. In most cases, the metal halide, high-pressure sodium (HPS) lamps and/or fluorescent lamps are used either as supplementary or sole-source (Kim et al. 2004). They are often inefficient for plant cultivation due to their fix and rather different spectral distribution than the solar light (Morrow 2008; Darko et al. 2014). The plants grown under these artificial light conditions often shows many symptoms of suboptimal light condition, such as internode elongation, shift in flowering time, decrease of fertility and low quality and quantity of crop production. In addition, these lamps have high energy consumption and high operation temperature make them economically inefficient (Kim et al. 2004, Morrow 2008).

Light emitting diodes (LED) represent an innovative artificial lighting source in plant cultivation. LEDs have low energy consumption, long-lifetime and small size, high fluence and variable spectral characteristics, which make them better suited to crop production than other artificial lighting systems (Morrow 2008). Therefore, the application of LEDs in agricultural/horticultural practice is increasing continuously. Cultivation of plants under LED lighting in environmentally controlled rooms enables standard vegetable production regardless of the weather conditions. The aim is to achieve high productivity and/or high vegetable quality without excess energy consumption. Changes of spectral composition could provide a solution for improving the yield and quality of crops.

Spinach (Spinacia oleracea) plants are widely cultivated in greenhouses throughout the world. This leafy green is rich in nutrients such as protein, dietary fiber, vitamins and folate and minerals such as $\mathrm{K}, \mathrm{Ca}, \mathrm{Mg}, \mathrm{Mn}$, and $\mathrm{Fe}$, which may play an important role in human nutrition and diet. Most studies on the effect of light intensity and spectral composition delivered by LEDs on the quality of leafy vegetables have focused on biomass 
production, leaf area and branching, while less is known about how LEDs affect the mineral composition and nutritional quality (Lin et al. 2013). In addition, spinach is less characterized than lettuce (Burattini et al. 2017).

This paper aims to determine whether similar productivity and/or quality can be achieved even under limited light intensity by changing of spectral composition of light. Therefore, spinach plants were cultivated under white light at low $\left(100 \mu \mathrm{mol} \mathrm{m}^{-2} \mathrm{~s}^{-1}\right)$,

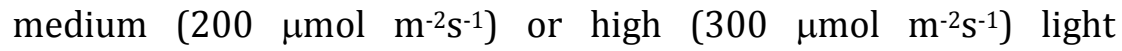
intensities and at white light $\left(200 \mu \mathrm{mol} \mathrm{m}^{-2} \mathrm{~s}^{-1}\right)$ with far-red or blue light supplementation in hydroponic growth conditions. The biomass production, leaf architecture will be compared together with the physiological response of plants, which was determined through monitoring the photosynthetic activity and chlorophyll contents of leaves. The leaf quality was estimated by determination of leaf protein, starch, and soluble sugar contents, by the measurements of nitrate, ascorbate, iron and potassium contents of plants grown under different light environment. We hope that this complex research brings a better understanding of the relationship of light conditions and yield quality and can provide further information for efficient indoor plant cultivation.

\section{MATERIALS AND METHODS}

\section{Plant cultivation}

Spinach (Spinacia oleracea L.) cv. Sparrow RZ F1 hybrid variety was used in the experiments. The seeds were germinated at $5^{\circ} \mathrm{C}$ for three days, then at $10^{\circ} \mathrm{C}$ for seven days and finally at $15^{\circ} \mathrm{C}$ for further 3 days. The plantlets were put into Jiffy coco plugs (Jiffy-7C, $50 \mathrm{~mm}$ std, Jiffy Products S.L. Ltd, Sri Lanka) and placed in phytotron growth chamber equipped with LED light sources and automatic control system for circulation of nutrient solution in the Agricultural Institute, Centre for Agricultural Research, Hungarian Academy of Sciences. The light characteristics used in the experiments are summarized in Table 1. Briefly, 3 different spectral compositions (White light, blue dominant white light and white light complemented with far-red radiation) at the same light intensity $\left(200 \mu \mathrm{mol} \mathrm{m} \mathrm{m}^{-2} \mathrm{~s}^{-1}\right)$ and 3 different light intensities (low: $100 \mu \mathrm{mol} \mathrm{m}{ }^{-2} \mathrm{~s}^{-1}$, medium: $200 \mu \mathrm{mol} \mathrm{m}^{-2} \mathrm{~s}^{-1}$ or high: $300 \mu \mathrm{mol} \mathrm{m}{ }^{-2} \mathrm{~s}^{-1}$ ) 
were used for spinach cultivation in hydroponic growth system using diluted Hoagland solution described by Pál et al. (2005). The $\mathrm{pH}$ and the ionic strength of the nutrient solution was kept between 6.0-6.5 and EC 1.1-0.9 respectively. Plants (at least 15 plants of each light regimen) were grown for 4 weeks at $20 / 15^{\circ} \mathrm{C}$ day/night temperature and $75 \%$ of humidity. The growth and development of spinach plants were monitored twice a week, and the measurements were started in the fourth week.

Table 1. The light spectral composition used in the experiment.

\begin{tabular}{lccccc}
\hline \multicolumn{5}{c}{ Light characteristics } \\
& $\begin{array}{c}\text { White } \\
\mathbf{3 0 0}\end{array}$ & $\begin{array}{c}\text { White } \\
\mathbf{2 0 0}\end{array}$ & $\begin{array}{c}\text { White } \\
\mathbf{1 0 0}\end{array}$ & $\begin{array}{c}\text { White } \\
\text { + FR 200 }\end{array}$ & $\begin{array}{c}\text { White } \\
\text { + Blue 200 }\end{array}$ \\
\hline $\begin{array}{l}\text { PAR (400-700nm) } \\
\mu \text { mol m }\end{array}$ & 310 & 202 & 100 & 205 & 208 \\
Ratio: & & & & & \\
Blue: Red & 0.208 & 0.200 & 0.184 & 0.189 & 4.86 \\
Red: Far-red & 8.0 & 8.8 & 10.2 & 1.0 & 9.2 \\
Blue: Far-red & 1.7 & 1.7 & 1.8 & 0.18 & 44.7 \\
\hline
\end{tabular}

12h/12h photoperiod were used.

\section{Determination of the photosynthetic activity of leaves}

The photosynthetic activity of plants was determined on intact leaves with a Ciras 3 Portable Photosynthesis System (Amesbury, USA) instrument using a narrow leaf area $\left(4.5 \mathrm{~cm}^{2}\right)$ chamber equipped with a chlorophyll $a$ fluorescence module. Since the Ciras 3 uses LED modules, the photosynthetic activity of leaves was measured under the same light conditions as was found in growth chambers. The net assimilation rate (A), stomatal conductance (gs), intracellular $\mathrm{CO}_{2}$ concentration (Ci) and transpiration (E), as well as the effective quantum yiled of PS II [Y(II)] were determined at the steady state of photosynthesis by the use of $400 \mu \mathrm{L} \mathrm{L}-1 \mathrm{CO}_{2}$ level.

\section{Determination of biomass production, leaf area and sample collection for the analytical investigations}

At harvest, the plant weight, leaf number and leaf area were determined in order to characterize the biomass production of plants. 10 plants of each light regimens were measured. The leaf area was determined using an Area Meter 500 from ADC 
Bioscientific Ltd. Then, samples for biochemical investigations were collected. Thus, 3 leaf discs (with $1.3 \mathrm{~cm}$ diameters) were collected from 5 plants (5 x 3 leaf discs) of each light regimen for determination pigment composition of leaves. Also, $5 \times 0.2 \mathrm{~g}$ samples were collected for determination of protein, starch, soluble carbohydrate and ascorbate content of leaves, respectively. In addition, samples were collected for determination of mineral ( $\mathrm{K}, \mathrm{Fe}$ and nitrate) content of leaves. The leaf samples were frozen immediately and stored at $-80^{\circ} \mathrm{C}$ until utilization.

\section{Analytical investigations}

Chlorophyll $a$ and $b$, as well as the carotenoid contents of leaf discs, were determined using a Cary-100 UV-Vis spectrophotometer (Varian, Middelburg, Netherlands) after extraction of leaf discs in 80\% acetone, according to the method of Lichtenthaler (1987).

The total protein content was determined according to the method of Bradford using bovine serum albumin as standard (Kruger 2009). Total soluble carbohydrates were extracted and measured following the method of Antron as described in Sinay and Karuwal (2014). The starch content was determined from twice-washed and dried pellet remaining after extraction of total soluble sugars according to the method of Thayumanavan and Sadasivam (1984).

Similar isolation protocol was used for determination of $\mathrm{K} \mathrm{NO}_{3}^{-}$, $\mathrm{Fe}$ and ascorbic acid contents. All compounds were diluted with MQ water $(1: 10)$. The measurements were performed by the use of RQflex plus 10 (Merck KGaA 64271 Darmstadt, Germany) instrument according to the manufacturer's instructions for $\mathrm{K}$ : 1.17945.000; $\mathrm{NO}_{3}^{-}$: 1.14761.0002; Fe: 1.14761 .0002 and Ascorbic acid: 1.16981 .000 .

\section{Statistical analyses}

The experiments were repeated 3 times. In each experiments at least 15 plants were grown under each light regimens and the samples were collected from randomy selected plants. The measuerements were repeated at least in 5 biological replicates. The data were analysed by SPSS 16.0 statistical program and Tukey's post hoc test were used to determine differences between treatments. Different letters indicate significant differences at the $\mathrm{P}$ $<0.05$ level. 


\section{RESULTS}

\section{Morphological responses of spinach cultivated under different light regimens}

To characterize the plants grown under different light environment several morphological parameters, such as leaf number, leaf area, and leaf mass were determined (Figure 1). All leaf mass, leaf area and leaf number increased with increasing of white light intensity (Figure 1A-C). However, the specific leaf area, the ratio of leaf area to leaf mass, decreased with increasing light intensity (Figure 1D). It is due to the fact that the increase of light intensity increased leaf area of plants with relatively less extent (3.23 and 4.47 fold change) than the leaf mass (they was 4.91 and 8.61 fold change). When the spectral composition of light was compared in grown of spinach plants at $200 \mu \mathrm{mol} \mathrm{m}{ }^{-2} \mathrm{~s}^{-1}$, the supplementation of white light with FR resulted in a slightly higher expansion of leaves and longer stems (data not shown) than without far-red application. Inversely, the blue light decreased the leaf area and created a compact and short plant. While the effect of spectrum in leaf area and weight were not significant, the specific leaf area increased under far-red and decreased when blue light was applied (Figure 1).

\section{Photosynthetic properties of spinach under different light environment}

Evidently light regulates the photosynthetic processes. As the light intensity increased, so did the $\mathrm{CO}_{2}$ assimilation rate (Pn), stomatal conductance (gs) and transpiration (E) in spinach leaves, meanwhile the intracellular $\mathrm{CO}_{2}$ level decreased (Figure 2). On the other hand, not only the intensity of the light, but the modification of spectral composition also influenced the $\mathrm{CO}_{2}$ assimilation processes: the blue light reduced and the FR light slightly (but not significantly) stimulated the $\mathrm{CO}_{2}$ assimilation capacity of plants (Figure 2A). However, the stomatal conductance changed inversely, it increased to blue and slightly decreased to far-red, when they were compared to white light having the same light intensity (Figure 2B). 

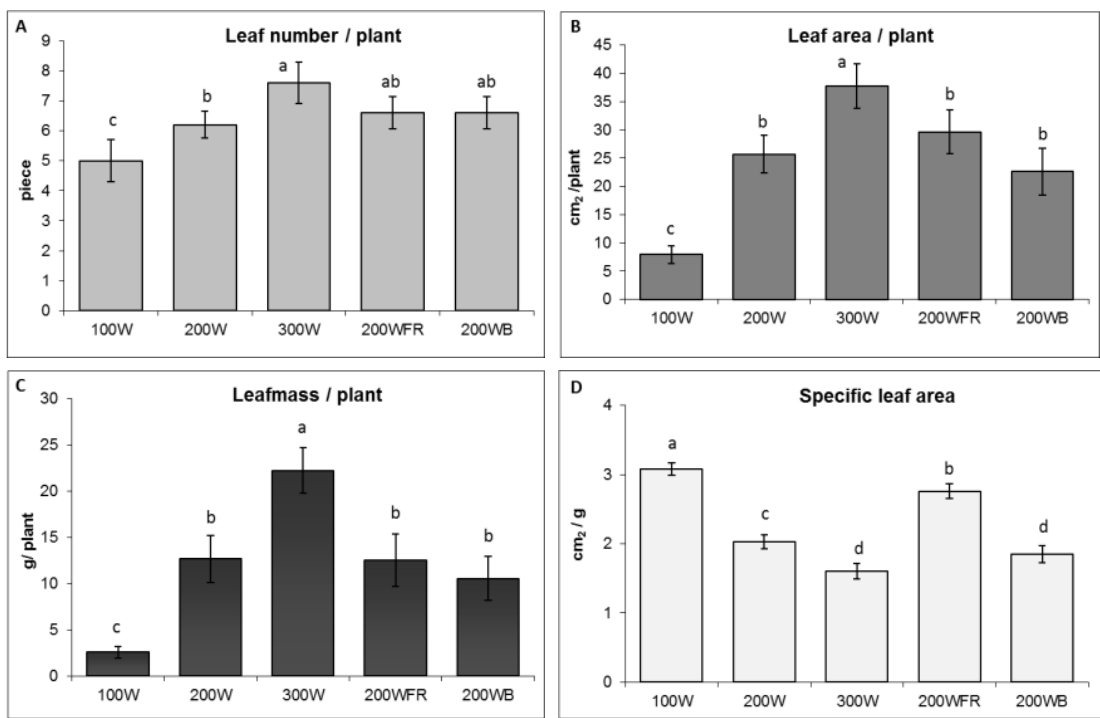

Figure 1. Effect of the light intensity and spectral composition on the growth parameters of spinach. A: Leaf number; B: Leaf area: C: Leaf mass; D: Specific leaf area. Values are the mean \pm STD of 10 biological replicates per light treatment. The different letters indicate statistically significant differences at $\mathrm{P}<0.05$, using Tukey's post hoc test.
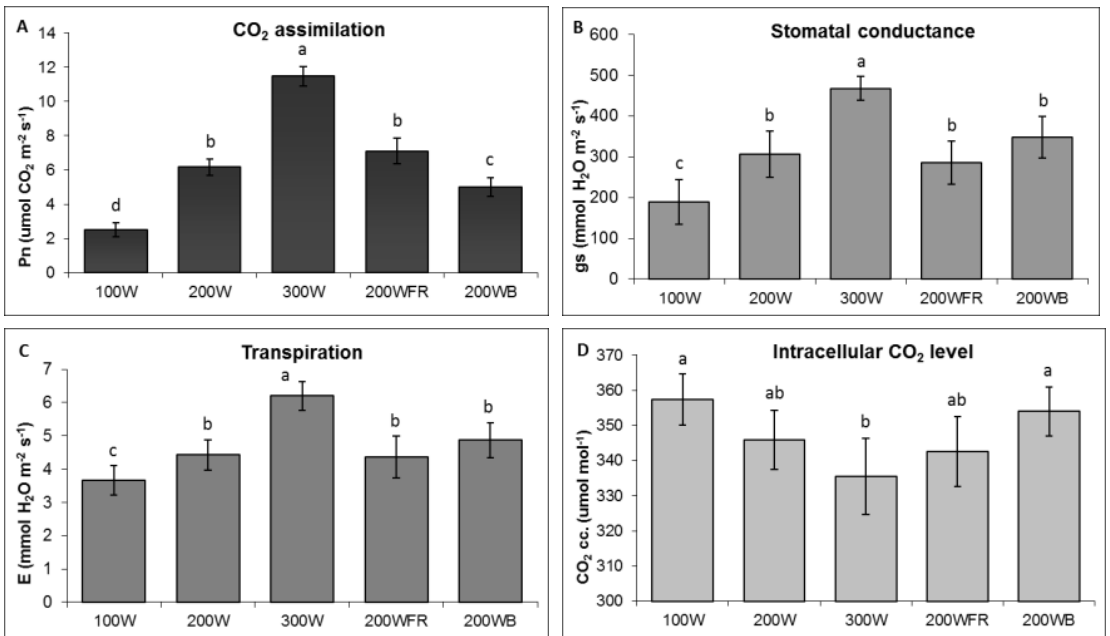

Figure 2. Comparison of photosynthetic properties of spinach leaves grown under different light regimens. A: Net $\mathrm{CO}_{2}$ assimilation rate (Pn); B: Stomatal conductance (gs); C: Transpiration (E) and D: Intercellular $\mathrm{CO}_{2}$ level. Values represent the means $( \pm$ STD) of 5 independent measurements per light treatment. The different letters indicate statistically significant differences at $\mathrm{P}<0.05$, using Tukey's post hoc test. 
The photosynthetic electron transport processes was also investigated. The effective quantum yield of PSII, Y(II), determined at steady of photosynthesis indicates the ratio of the number of photons utilized photochemically/total number of quanta absorbed. Typically, the conversion ratio of absorbed light energy to photochemistry in PS II decreased in parallel to the increase of light intensity in spinach leaves, which was indicated by the lower Y(II) values (Figure 3). Lower Y(II) was also measured in leaves grown under the blue light as compared to those plants grown under white light at the same light intensity with or without FR application. In fact, Y(II) values were similar in spinach leaves grown under blue light at $200 \mu \mathrm{mol} \mathrm{m}^{-2} \mathrm{~s}^{-1}$ and under white light at $300 \mu \mathrm{mol} \mathrm{m}^{-2} \mathrm{~s}^{-1}$.

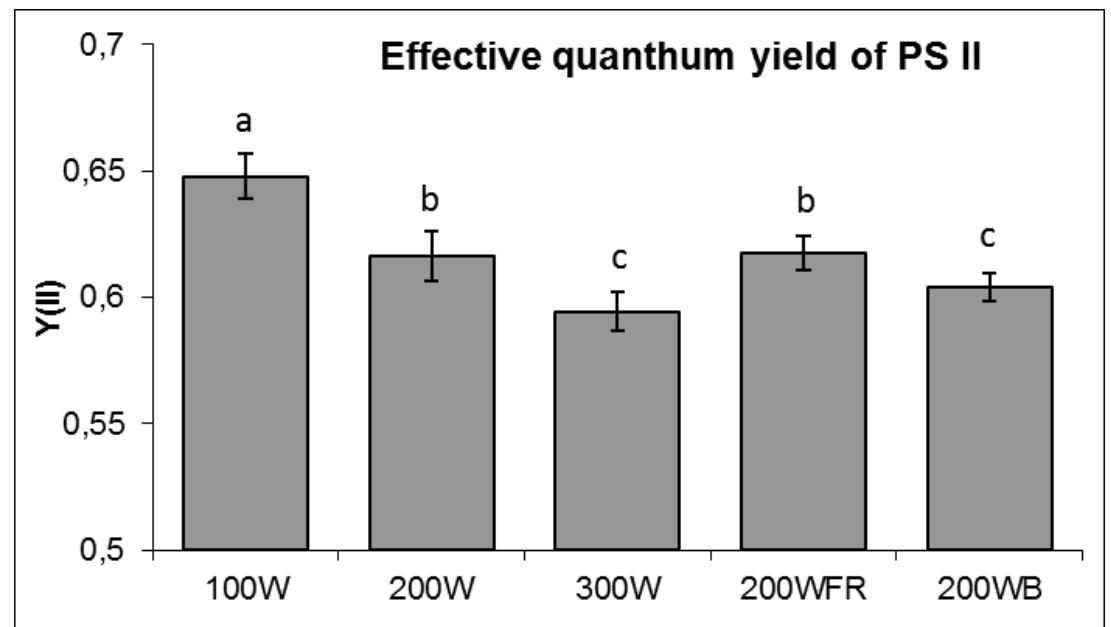

Figure 3. Photochemical utilization of absorbed light energy determined in spinach leaves grown under different light conditions at steady state level of photosynthesis. Y(II) - effective quantum yield of PSII photochemistry. Values represent the means $( \pm$ STD) of 5 independent measurements per light treatment. The different letters indicate statistically significant differences at $\mathrm{P}<0.05$, using Tukey's post hoc test.

When the pigment composition of leaves grown under different light regimens were compared, two interesting tendency was observed: the pigment composition hardly varied in the function of light intensity, but changed according to the spectral composition (Table 2). The lowest chlorophyll $a$ and b contents were detected in plants grown under blue light, followed by the highest light 
intensity, while the highest chlorophylls were detected when FR was applied.

These results suggest that both the light fluence and spectral composition determines the photosynthetic properties of plants.

Table 2. Effect of the light intensity and spectral composition on chlorophyll $(a+b)$ and carotenoid contents of leaves.

\begin{tabular}{lccccc}
\hline \multicolumn{7}{c}{ Pigment composition } \\
\hline$\mu \mathrm{g} / \mathrm{g} \mathrm{FW}$ & $\mathbf{3 0 0}$ & $\mathbf{2 0 0}$ & $\mathbf{1 0 0}$ & $\begin{array}{c}\text { White } \\
\text { + FR 200 }\end{array}$ & $\begin{array}{c}\text { White } \\
\text { + Blue 200 }\end{array}$ \\
\hline $\mathrm{Chl} \mathrm{a}+\mathrm{b}$ & $1498 \pm 126 \mathrm{~b}$ & $1853 \pm 189 \mathrm{a}$ & $1760 \pm 186 \mathrm{a}$ & $1855 \pm 205 \mathrm{a}$ & $1390 \pm 215 \mathrm{~b}$ \\
Carotenoids & $332 \pm 47 \mathrm{a}$ & $378 \pm 37 \mathrm{a}$ & $334 \pm 32 \mathrm{a}$ & $329 \pm 37 \mathrm{a}$ & $300 \pm 42 \mathrm{a}$ \\
$\mathrm{Chl} \mathrm{a} / \mathrm{b}$ & $2.97 \pm 0.33 \mathrm{a}$ & $3.27 \pm 0.20 \mathrm{a}$ & $3.44 \pm 0.22 \mathrm{a}$ & $3.08 \pm 0.21 \mathrm{a}$ & $3.41 \pm 0.20 \mathrm{a}$ \\
$\mathrm{Chl} / \mathrm{Car}$ & $4.51 \pm 0.38 \mathrm{~b}$ & $4.90 \pm 0.36 \mathrm{~b}$ & $5.27 \pm 0.34 \mathrm{ab}$ & $5.63 \pm 0.28 \mathrm{a}$ & $4.62 \pm 0.44 \mathrm{~b}$ \\
\hline
\end{tabular}

\section{Effect of light intensity and spectral composition on the yield quality of spinach leaves}

The leaf quality was estimated by determination of leaf protein, starch, and soluble sugar contents and by the measurements of nitrate, ascorbate, iron and potassium contents of plants grown under different light environment (Figure 4).

The primary metabolites, such as the soluble sugars, starch and proteins increased with increasing light intensity in spinach leaves (Figure $4 A-C$ ). It was mainly due to the light-dependent increase of the photosynthetic activity. Blue light stimulated the protein accumulation, while decreased significantly the amount of soluble sugars and starch in spinach leaves as compared to white light used at the same light intensity. The supplementation of white light with far-red resulted in a significant accumulation of soluble sugars, while the proteins level decreased to the similar value found in leaves grown under low $\left(100 \mu \mathrm{mol} \mathrm{m} \mathrm{m}^{-2} \mathrm{~s}^{-1}\right)$ light intensity (Figure $4 A)$.

Spinach is an excellent source of vitamin C. The amount of ascorbate was hardly affected by light intensity and spectral composition (Figure 4D). Significant increase in ascorbate content was detected only when high proportion of blue light was applied. 

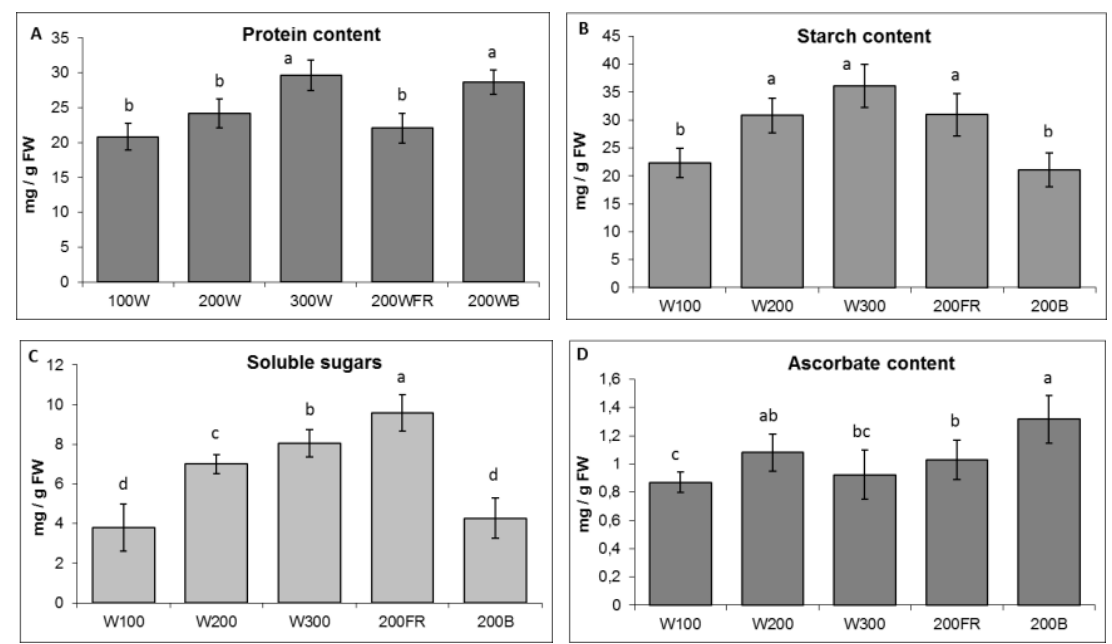

Figure 4. Production of primary and secondary metabolites in spinach leaves grown under different light regimens. A: protein content; B: starch content; C: soluble sugar content; D: ascorbate content. Values are the mean \pm STD of 5 biological replicates per light treatment. The different letters indicate statistically significant differences at $\mathrm{P}<0.05$, using Tukey's post hoc test.
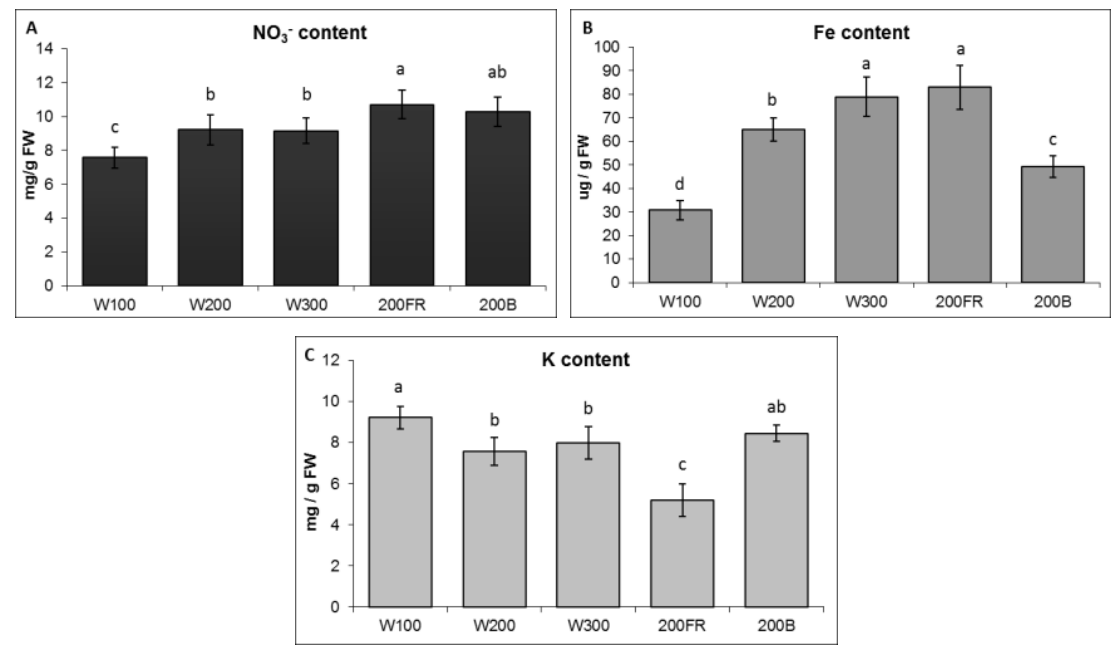

Figure 5. Mineral content of spinach leaves grown under different light regimens. A: nitrate content; B: iron content; C: potassium content; Values are the mean \pm STD of 5 biological replicates per light treatment. The different letters indicate statistically significant differences at $\mathrm{P}<0.05$, using Tukey's post hoc test. 
Among minerals, the $\mathrm{K}, \mathrm{Fe}$ and $\mathrm{NO}_{3}{ }^{-}$content of leaves were determined (Figure 5). Surpisingly, only the accumulation of Fe showed ligh intensity dependent changes in spinach (Figure 5B). Neither the $\mathrm{NO}_{3}^{-}$nor the K content showed similar tendency (Figure $A$ and $C$ ). The spectral composition influenced both the iron and the potassium content of leaves. The blue light reduced the accumulation of $\mathrm{Fe}$, while far-red decreased the $\mathrm{K}$ content of leaves (Figure 5B and $C$ ). All these modifications affects the yiled quality of spinach.

\section{DISCUSSION}

Cultivation of leafy plants under artificial lighting becomes more and more important in the future to produce high quality and quantity of foods throughout year. They are influenced by both light fluence and spectral composition. Providing variable fluence and spectral composition, LEDs give a unique possibility to optimize the growth conditions.

Through activation of photosynthetic processes, the increase of light intensity forces the biomass production which in case of leafy plants, manifests in the increase of leaf number, area and mass. In our experiments it seemed that the biomass production was mainly determined by the light intensity while the spectral composition was less influenced. However, the increase of photosynthetic activity induced leaf expansion less than producing assimilates, resulting in a decrease of sepcific leaf area. This phenomenon (e.g. sepcific leaf area decreased with increasing light intensity) was also observed by Xiao-Xue et al. (2013) and Urrestarazu et al. (2016). In the opinion of Gommers et al. (2013), this response to light could help plants to increase the efficiency of light capture and maximize carbon gain at low light intensity (Gommers et al. 2013). It can help plants under shade environment. Our results can support it, since the specific leaf area $\left(\mathrm{cm}^{2} / \mathrm{g}\right)$ also increased when the white light was supplemented with far-red light. However, it should be mentioned that the application of far-red light resulted in weak and thin leaves (data not shown). Inversely blue light inhibited the leaf expansion thus decreased the specific leaf area and increased the leaf thickness (it was observed, but not measured), similarly as was found at higher light intensity by us and by Meziane and Shipley (1999). 
Photosynthetic pigments absorb and convert the light energy into chemical energy via complex photosynthetic machinery. Blue and red light play an active role in photosynthesis and also stimulate chlorophyll and carotenoid biosynthesis (Xiao-Xue et al. 2013, Wang et al. 2015). In the present study, light intensity caused the largest effects on photosynthetic processes, which were manifested in elevated $\mathrm{CO}_{2}$ assimilation capacities, induction of stomata opening and transpiration, and also in the decreased ratio in the conversion of absorbed light energy to photochemistry in PS II, as demonstrated by the low Y(II) value. However, not only the light intensity but also its spectral composition affects $\mathrm{CO}_{2}$ assimilation processes. The blue light decreased the $\mathrm{CO}_{2}$ assimilation, while stimulated the stomatal opening. Kim et al. (2004) also found that the high proportion of blue light decreased the $\mathrm{CO}_{2}$ assimilate rate, in spite of the fact that blue light stimulated the stomatal opening. The blue light-induced stomatal movement is explained by (Kinoshita and Hayashi 2011), who found that the blue light-induced stomatal opening is mediated by phototropins (activate by blue light) through the activation of the plasma membrane $\mathrm{H}^{+}$-ATPase in guard cells. When the effects of blue light were studied on cucumber plants grown under different combinations (0-100\%) of red and blue light, Hogewoning et al. (2010) was found that the blue light provided 'sun-type' characteristics of leaves even at the relatively low growth irradiance. Blue light overexcited the PS II reaction centres resulting in a lower photochemical utilization of absorbed light energy at PS II, similarly as was found under higher light intensity. We also found the decrease of Y(II) when blue light was applied. A relative overexcitation of PSII can results in an imbalance of photosynthetic electron transport between PS II and PS I, which can decrease the efficiency of the photosynthetic processes. In addition, the blue light-induced 'sun-type' characteristics of leaves was manifested also in the decrease of chlorophylls in spinach leaves, similarly as was found by Zhang et al. (2016) and Monostori et al. (2018). To ensure the optimal growth a fine balance between the blue and red ratio is necessary to provide equilibrated and efficient utilization of absorbed light energy between the PS II and PS I.

While it is widely understood that light intensity can positively affect the accumulation of assimilates, the effects of light quality is 
more complex. In this way, the higher light intensity was used, the more primary assimilates including proteins, starch and sugars were produced in spinach leaves. But, light quality also affected the production of primary and secondary metabolites in spinach leaves. Blue light significantly increased protein and ascorbate contents of leaves, while less sugar and starch were accumulated in these plants. In fact, when the plants were grown under white light supplemented with blue, as high protein and ascorbate content was obtained at $200 \mu \mathrm{mol} \mathrm{m}^{-2} \mathrm{~s}^{-1}$ light intensity as plants achieved under higher $300 \mu \mathrm{mol} \mathrm{m}^{-2} \mathrm{~s}^{-1}$ light intensity. On the other hand, when the light was completed with far-red light the spinach leaves contained more sugars and Fe than in any other cases. The blue-light induced shift in protein and ascorbate metabolism was also detected in lettuce (Chen et al. 2016). However, the reason of protein accumulation is controversial. As the nitrate provides main $\mathrm{N}$ source in proteins of plants, it was suppose that the high protein content is originated from the elevated nitrate uptake. However, when Zhang et al. (2018) compared the effect of different LEDs (white, red and blue in different proportion) on the nitrogen metabolism in lettuce, they found that both red and blue light promoted the $\mathrm{N}$ assimilation by improving the activity of the $\mathrm{N}$ metabolism-related enzymes such as nitrate and nitrite reductases, in lettuce. In other studies, it was found that the nitrate reductase activity was stimulated by red light. Samuoliené et al. (2009) used high-intensity red LEDs treatment 3 days prior to harvets to reduce the nitrate content in lettuce. It can be useful, especially in case of leafy plants. However, our results can not prove these findings since the accumulation of nitrates did not change either by light intensity (except at low light, when the low transpiration reduced the nitrate and any kind of ion uptakes) or by spectral composition. Nevertheless, the physiological significance of LED-induced regulation of nitogen metabolism remained undercharacterized.

\section{CONCLUSION}

Although the mechanisms of the changes in spinach growth under LED lighting are not well understood yet, the results showed that LED light can be used to modify the plant growth and metabolism in spinach. Via the variable fluence and spectral composition, the LEDs provide a unique possibility to change both the light intensity 
and the spectral composition during the lifetime of plants in order to ensure the best light combinations resulting in the highest nutritional values of leafy plants in indoor plant cultivation. On the bases of the results it seems that white light at adequately high intensity $\left(300 \mu \mathrm{mol} \mathrm{m} \mathrm{m}^{-2} \mathrm{~s}^{-1}\right)$ can ensure the optimal growth for spinach to reach the harvest quality in 4 weeks.

At the early developmental stage the application of far-red can induce leaf expansion, while before harvest the increase of the proportion of blue light can stimulate the accumulation of proteins and ascorbate content, which can improve the leaf quality. However, the appliaction of red or far-red light can increase the sugar content, which imporve the sweetness of leaves. Anyway, although the LEDs are suitable for manipulation the growth and metabolism in plants, it is unlikely that only one spectral combination can ensure the optimal growth and yield quality throughout the life cycle.

Acknowledgements - This work was supported by the TÁMOP 4.2.2.A11/1/KONV-2012-0008 project.

\section{REFERENCES}

Burattini, C., Mattoni, B. \& Bisegna, F. (2017). The impact of spectral composition of white LEDs on spinach (Spinacia oleracea) growth and development. Energies 10(9): 1383. https://doi.org/10.3390/en10091383

Chen, X., Xue, X., Guo, W., Wang, L. \& QIAo, X. (2016). Growth and nutritional properties of lettuce affected by mixed irradiation of white and supplemental light provided by ligh-emitting diode. Scientia Horticultrae 200: 111-118. https://doi.org/10.1016/j.scienta.2016.01.007

Darko, E., Heydarizadeh, P., Schoefs, B., \& Sabzalian, M.R. (2014). Photosynthesis under artificial light: the shift in primary and secondary metabolism. Philosophical Transactions of the Royal Society B: Biological Sciences 369(1640): 20130243. https://doi.org/10.1098/rstb.2013.0243

Gommers, C.M.M, VisSer, E.J.W., Onge, K.R.S., VoeseneK, L.A.C.J. \& PieriK, R. (2013). Shade tolerance: when growing tall is not an option. Trends in Plant Science 18: 65-71. https://doi.org/10.1016/j.tplants.2012.09.008

Hogewoning, S.W., Douwstra, P., Trouwborst, G., van Ieperen, W. \& Harbinson, J. (2010). An artificial solar spectrum substantially alters plant development compared with usual climate room irradiance spectra. Journal of Experimental Botany 61: 1267-1276. https://doi.org/10.1093/jxb/erq005

Kim, H.H., GoINS, G.D., WHEELER, R.M. \& SAGER, J.C. (2004). Green-light supplementation for enhanced lettuce growth under red-and blue lightemitting diodes. HortScience 39(7): 1617-1622.

https://doi.org/10.21273/HORTSCI.39.7.1617 
Kinoshita, T. \& Hayashi, Y. (2011). New Insights into the Regulation of Stomatal Opening by Blue Light and Plasma Membrane H+-ATPase. International Review of Cell and Molecular Biology 289: 89-115.

https://doi.org/10.1016/B978-0-12-386039-2.00003-1

KRUGER, N.J. (2009). The Bradford method for protein quantitation. Humana Press, Totowa, N.J., pp. 17-24.

LichtenthaleR, H.K. (1987). Chlorophylls and Carotenoids: Pigments of Photosynthetic Biomembranes. In: Methods in Enzymology 148: 350-382. https://doi.org/10.1016/0076-6879(87)48036-1

Lin, K-H., Meng-Yuan, H., Wen-Dar, H., Ming-Huang, H., Zhi-Wei Y. \& Chi-Ming. Y. (2013). The effects of red, blue and white light-emitting diodes (LEDs) on growth, development and edible quality of hydroponically grown lettuce (Lactuca sativa L. var. capitata). Scientia Horticulturae 150: 86-91. https://doi.org/10.1016/j.scienta.2012.10.002

Meziane, D. \& Shipley, B. (1999). Interacting determinants of specific leaf area in 22 herbaceous species: Effects of irradiance and nutrient availability. Plant, Cell and Environment 22: 447-459. https://doi.org/10.1046/j.13653040.1999.00423.x

Monostori, I., Heilmann, M., Kocsy, G., Galiba, G. \& Darko, E. (2018). LED Lighting Modification of growth, metabolism, yield and flour composition in wheat by spectral quality and intensity. Frontiers in Plant Science 9: 605. https://doi.org/10.3389/fpls.2018.00605

Morrow, R.C. (2008). LED Lighting in Horticulture. HortScience 43: 1947-1950. https://doi.org/10.21273/HORTSCI.43.7.1947

PÁl, M., Horváth, E., JANDA, T., PÁLDI, E. \& Szalai, G. (2005). Cadmium stimulates the accumulation of salicylic acid and its putative precursors in maize (Zea mays) plants. Physiologia Plantarum 125: 356-364.

https://doi.org/10.1111/j.1399-3054.2005.00545.x

Samuoliene, G., Urbonaviciüte A., Duchovskis, P., Vitta, P. \& Zukauskas, A. (2009). Decrease in nitrate concentration in leafy vegetables under a solid-state illuminator. HortScience 44: 1857-1860.

https://doi.org/10.21273/HORTSCI.44.7.1857

SinAY, H. \& KaruWAL, R.L. (2014). Proline and total soluble sugar content at the vegetative phase of six corn cultivars. International Journal of Advance Agricultural Reseach 2: 77-82.

THAYUMANAVAN, B. \& SADASVIAM, S. (1984). Estimation of starch by anthrone reagent - Carbohydrates | Laboratory Methodology. [Retrieved: 25.04.2019], from https://biocyclopedia.com/index/plant_protocols/carbohydrates/starch_by_a nthrone_reagent.php

Urrestarazu, M., NÁjera, C. \& Gea, M. (2016). Effect of the Spectral Quality and Intensity of Light-emitting Diodes on Several Horticultural Crops. HortScience 51: 268-271. https://doi.org/10.21273/HORTSCI.51.3.268

WANG, Z., Tian, J., YU, B., YANG, L., \& SUn, Y. (2015). LED Light Spectrum Affects the Photosynthetic Performance of Houttuynia Cordata Seedlings. American Journal of Optics and Photonics 3: 38-42. https://doi.org/10.11648/j.ajop.20150303.12

Xiao-Xue, F., Zhi-Gang, X., XiaO-Ying, L., CAN-Ming, T., Li-Wen W., \& Xue-Lin H. (2013). Effects of light intensity on the growth and leaf development of young tomato 
plants grown under a combination of red and blue light. Scientia Horticulturae 153: 50-55. https://doi.org/10.1016/j.scienta.2013.01.017

Zhang, T., SHI, Y., PIAO, F. \& SUn, Z. (2018). Effect of different LED sources on the growth and nitrogen metabolism in lettuce. Plant, Cell, Tissue and Organ Culture 134: 231-240. https://doi.org/10.1007/s11240-018-1415-8

(submitted: 15.12.2018, accepted: 07.05.2019) 